Print ISSN: ISSN 2054-6424(Print), Online ISSN: ISSN 2054-6432(Online)

\title{
SYSTEM QUALITY AND ECONOMIC SUSTAINABILITY OF NIGERIAN TOURIST SITES: A LEADERSHIP CHALLENGE FOR OPERATIONS MANAGERS
}

\author{
${ }^{1}$ Ndu, Eugene Chigozie (PhD) and ${ }^{2}$ Umoh, Godwin Ikpe (Professor) \\ ${ }^{1}$ Department of Hospitality Management and Tourism, Faculty of Management Sciences, \\ University of Port Harcourt. \\ ${ }^{2}$ Department of Management, Faculty of Management Sciences, University of Port Harcourt.
}

\begin{abstract}
The challenge of economic sustainability of Nigerian tourist sites calls for effective operations management engendered by quality systems. Hence, this study sought to ascertain the relationship between system quality (dimensioned by system reliability, system efficiency, system flexibility and system privacy) and economic sustainability; giving rise to four hypotheses. Survey design was adopted; with a sample of 328 respondents drawn from 55 tourist sites in the South-South and South-East zones of Nigeria. Data were analysed using mean and standard deviation techniques; as well as the structural equation modelling techniques. Results showed good model fit for the measurement models and significant direct relationships for the structural models. It was concluded that system quality is an antecedent of economic sustainability; and the dimensions thereof are good predictors of economic sustainability. The study recommended that operations managers should endeavour to design and re-design tourist facilities in such a way that the system can be relied upon for quality output; they should ensure that the system is designed and/or re-designed in ways that can adapt to changing demands and technological improvements; while features that help ensure safety, personalized needs, environmental friendliness etc., must consciously be incorporated into such designs.
\end{abstract}

KEYWORDS: system design, system efficiency, system flexibility, system privacy, system reliability, tourism attraction and tourism facilities.

\section{INTRODUCTION}

The phenomenology of economic sustainability (ES) has become a major challenge to societies; especially, the developing ones. This has jostled organizational leaderships while calling to question their operations management capabilities. Ostensibly, the leadership challenge here is that of keeping the organization within the space of acceptable state; which must be economically sound, socially acceptable, administratively prudent, politically feasible, wider-system friendly and environmentally sustainable (Siriram, 2011). One possible way of achieving Economic Sustainability (ES) is through sustainable tourism development (STD) anchored on quality systems; hence this study which focused on establishing the relationship between system quality (SysQ) and ES as viewed from the lens of operations management.

No doubt, modern day tourism has assumed a global importance that makes it significant and relevant for the economy of nations. It has been described as an essential activity for the continued existence of nations due to its direct effects on the economic, social, cultural and educational sectors of the national societies; as well as on their international relationships 
(Ekundayo \& Abutu, 2015, p. 2). This has been buttressed by the 2017 tourism report in which tourism was described as one of the fastest and largest growing industries of the world (United Nations World Tourism Organization [UNWTO], 2017); and continues to grow in spite of the complex nature of its operating environment. According to the report, the industry recorded outstanding and impressive performance despite continuing economic challenges of global magnitude and changes ensuing from geopolitical altercations. Based on the excerpts from the UNWTO's tourism highlights of 2017, there is continued increase in the number of newly opened destinations and investments in tourism, making the sector a key driver of socioeconomic growth via job creation, businesses, avenues for export and infrastructural development. In spite of occasional shocks which demonstrate the sector's resilience and strength, it has boasted virtually of uninterrupted expansion and growth over time. As at 2016, international tourist arrivals had increased from 25 million globally in 1950 to 278 million in 1980, 674 million in 2000 and 1,235 million (1.235 billion) in 2016. This represents a $3.9 \%$ growth rate, increase of 46 million over the previous year. International tourism receipts grew from US\$2 billion in 1950, to US\$104 billion in 1980, US\$ 495 billion in 2000 and US\$1,220 billion (i.e. US $\$ 1.22$ trillion) in 2016. This represents a $2.6 \%$ growth rate in real terms. Likewise, international tourism exports in 2016 stood at US\$ 1.4 trillion, averaging US\$ 4billion a day; and accounting for 7\% of world's exports. In terms of world's gross domestic product (GDP), the sector accounted for $10 \%$ of global GDP in 2016. The sector equally accounted for 1 in 10 jobs in 2016 representing 10\% of total global job creation; while international tourist arrival is estimated to reach 1.8 billion by 2030 .

These impressive statistics indicate that tourism is a veritable instrument for achieving sustainability in term of economic development (Zamfir \& Corbos, 2015). Sustainable development (SD) is development that meets the present needs of humans without jeopardizing or compromising the ability of future generations to meet their own needs (United Nations World Commission on the Environment and Development [WCED], 1987, p. 42). Sustainable economic development (SED) could be seen as development that ensures practicable, longterm economic operations, offering socio-economic benefits to fairly distributed applicable stakeholders, including opportunities for income-generation, stable employment and provision of social services to host communities; as well as contributing to the alleviation of poverty (UNWTO, 2004). When this is related to tourist sites, it means the development of tourist sites in such a way that they portend or engender the qualities and characteristics described above. Identified themes include revenue generation, employment generation and economic empowerment of locals through small scale business development (UNWTO, 2004).

The potential benefits of SED are not far-fetched in Nigeria; as the society is richly blessed with tourist sites that when properly developed and efficiently managed are capable of engendering sustainable development. This was succinctly captured by Umoh and Ndu (2013), when they espoused that the country is blessed with locations such as beaches, magnificent waterfalls, unique wildlife, tropical forest and great works of art showcasing the lifestyle and creativity of the people. According to them, these features place Nigeria on a vantage position with the potential of attracting tourists into the country; and diversifying her economy thereby. These budding benefits synchronize with the tenets of economic sustainability which aims at maintaining economic advancement and progress while protecting the long-term value of the environment (United Nations General Assembly (UNGA), 1987, p. 43). However, the achievement of economic sustainability (ES) requires formidable systems that drive the 
required quality processes; hence the need for systems quality. It must be emphasized here that different systems exist; but the quality of the systems is what determines the extent to which the desired output in terms of ES is realized.

System Quality (SysQ) has been described as a reflection of the service users' perceptions of the technicality of the communication level of a system (Akter, Wamba \& D'Ambra, 2016; Delone, 2003). For the purpose of this study, it is taken to mean the system users' perceptions of the level of technicality of a service delivery system in the tourist site. It reflects the ability of the system to deliver what it is intended to deliver; and consequently engender trust and confidence in the system's ability. The acknowledged dimensions comprise system reliability, system efficiency, system flexibility and system privacy (Akter et al, 2016; Delone, 2003; Nelson, Todd \& Wixom, 2005; Parasuraman, Ziethaml and Berryl, 2005). System reliability is an indication of the extent to which the system is dependable over time (Delone, 2013; Parasuraman et al, 2005) in delivering what it had promised to deliver. System efficiency specifies the extent to which the service system can be easily used (Parasuraman, et al, 2005). System flexibility is a measure of the extent to which the service system is adaptable to different user needs and changing service conditions (Akter et al, 2016; Delone, 2003; Nelson et al, 2005; Parasuraman et al, 2005). The last sub-dimension system privacy reflects the extent to which the service system protects the privacy of the patient's health information (Akter et al, 2016; Parasuraman et al, 2005); but has been adapted for this study to mean a reflection of the extent to which the service system provides some level of privacy of the tourist's identity or confidentiality to the user who so desires.

Several studies have linked SysQ to outcome measures like satisfaction (Al-Ababneh 2017; Akter et al, 2016; Kuo, Chou \& Sun, 2011), customer loyalty (Al-Ababneh 2017; Haghkah, Ebrahimpuor, Hamid, \& Abdul-Rasid, 2016), re-visit intention (Akter et al, 2016; Haghkhah et al, 2016; Perera \& Vlosky, 2013; Shonk \& Chelladurai, 2008; Zabkar, et al, 2010), operating performance / effectiveness (Andreassen et al, 2016; Chou, Kim, Tsai, Yeh \& Son, 2017; Heskett, Sasser \& Schlesinger, 1997), service delivery (Chinjavata, Lubbe, \& Klopper, 2015), tourism development (Haghkhah et al, 2016) etc. Specifically, Haghkhah et al (2016) used their study which was based on service quality and the tourism industry to find that the quality of accommodation, accessibility, venue and their components have direct, positive and significant, relationships with tourists' satisfaction, their intent to return and eventually tourism development in a region. Similarly, Chou et al (2017) used their study "Longitudinal assessment of high-speed rail service delivery, satisfaction and operations: A study of Taiwan and Korea systems" to conclude that good service quality and corporate image are essential for good operating performance. As laudable as these studies are, none of them specifically related the construct of SysQ to ES. Moreover, these studies were domiciled in countries outside Nigeria; thereby orchestrating the need for this study which sought to examine and possibly establish the relationship between SysQ and ES.

The problem of this study stems from the poor quality of our tourism systems which has limited the full realization of the supposed economic benefits of tourism development in Nigeria as marshalled out earlier in this study. Unbelievably puzzling is the criticality of the predicament in a good number of tourist sites in Nigeria; which indicate unattractive facilities and sites, dampened employee morale cum poor service delivery, low visitors' patronage and involvement, low international/national tourist arrivals, low tourism exports, low involvement 
of tourist site communities etc. Though statistics show that international tourism receipts improved from US\$404 million in 2015 to US\$ 1.070 billion in 2016; it is quite low when compared to the impressive performance of tourist destinations like USA, Spain, China, France, South Africa, Tanzania, Mauritius and Botswana (UNWTO, 2017, pp. 8-11). Domestic tourism is also on the decline as observed by key players in the nation's tourism industry (Awunor, 2017). According to Awunor, a recent visit to Tinapa Resort Calabar by the nation's Senate committee chairman on Capital Market had the senator lament that "there are many tourist sites in Nigeria which were not being fully utilized; and that local tourist/attraction centres just lie fallow in their various locations". The resultant effect is untapped potentials and undeveloped resources; leading to loss of revenues, jobs, undeveloped/underdeveloped human capital and culture seclusion or as in the words of Cooke (2015), 'cultural isolationism'. Symptomatically, this quandary can be substantiated in the desire of many Nigerian holiday makers to choose destinations outside Nigeria for the satisfaction of their tourism desires. Thus, they prefer spending more resources to go to places like South Africa, Ghana, Kenya, Dubai, London etc.; whereas several of our tourist sites are begging for visitors. These are indicative of some of the challenges plaguing the Nigerian tourist sites as evidenced in some other scholarly works (Adora, 2010; Anuwor, 2017; Okpolo \& Okpolo, 2002; Umoh \& Ndu, 2013). In a bid to proffer solution to these challenges, laudable solutions have been advocated, with most of them focusing on the role of government in mollifying the problems (Adora, 2010; Anuwor, 2017; Okpolo \& Okpolo, 2002; Ayeni \& Ebohon, 2013) while neglecting the inherent poor quality of our tourism systems. This study therefore is a marked departure from the usual 'government should' approach; to a more inclusive methodology which focused on using the afore mentioned dimensions of SysQ (reliability, efficiency, flexibility and privacy) to X-ray their relationship with ES and how operations managers can leverage on this to achieve sustained economic development. This anticipated relationship has been shown in a model as depicted in figure 1. 


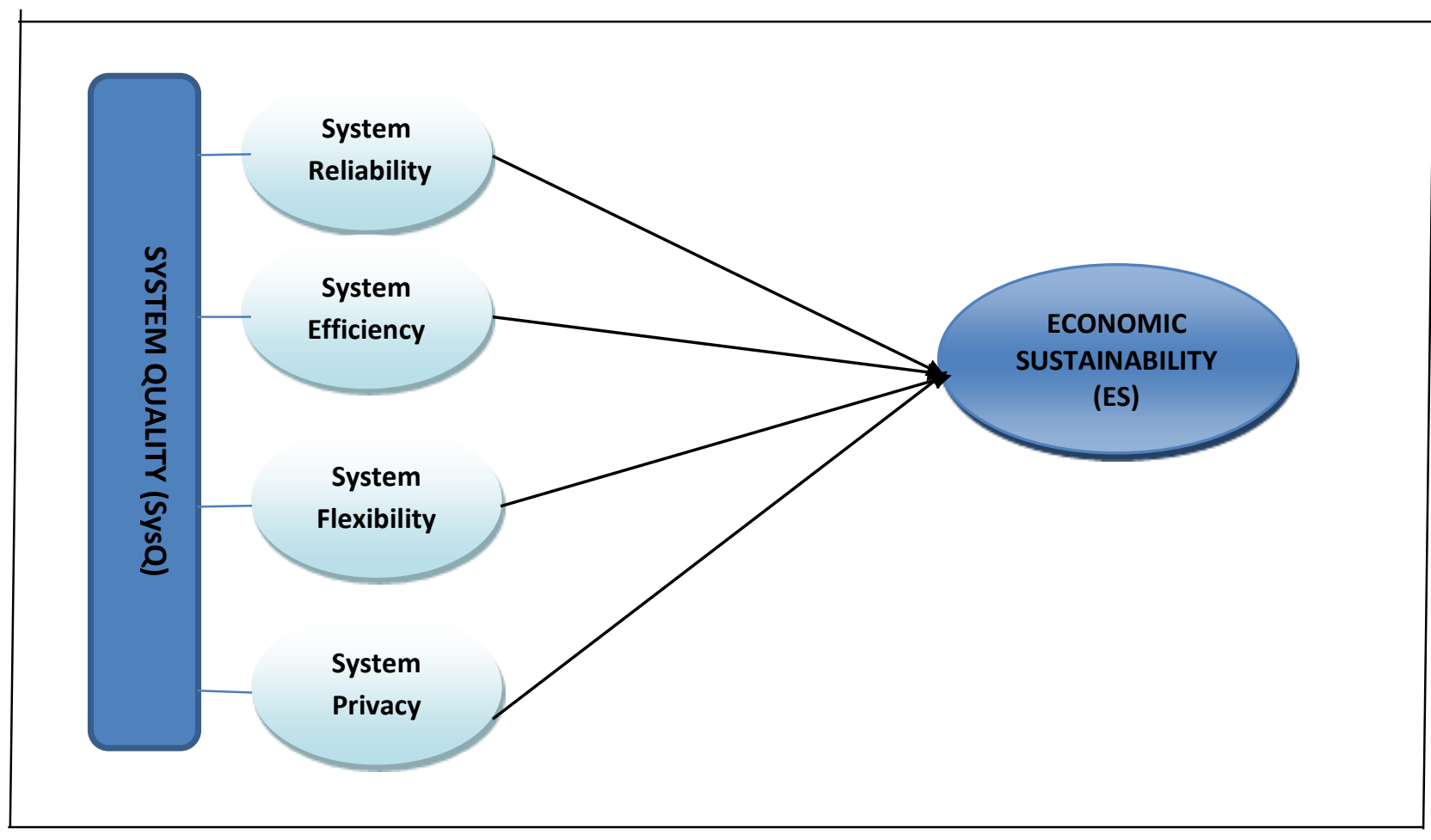

Fig. 1: Conceptual Model of the Relationship between System Quality and Economic Sustainability

Source: Researchers Conceptualization based on Dimensions Adapted from Akter et al (2016).

Figure 1 shows that SysQ has four dimensions; with the arrowed lines showing the anticipated relationship between each of the dimensions of SysQ and the criterion variable ES. Thus, the objectives of the study were to:

1. Discover the relationship between system reliability and ES.

2. Explore the relationship between system efficiency and ES.

3. Ascertain the relationship between system flexibility and ES.

4. Examine the relationship between system privacy and ES.

It is expected that this study will contribute to the staple of knowledge on the subject matter. Specifically, the deep literature base, the logical sequencing and the compelling analysis will not only engage an avid reader, but leave him with an overdose of academic comestibles to grapple with. Tourist site managers and other interested parties can use this study to gain deeper insights on the quality of their systems and how to design their systems to so reflect the desired quality. They will also learn the importance of adopting the systemic approach in the management of their organizations. The study equally addressed the need for tourism systems in Nigeria to measure up to international standards and possibly be at par with global benchmarks. By so doing, it stressed the need for tourist site operators (operations managers) to adopt global best practices in designing their systems for good service delivery; so that maximum value can be derived from them; especially, the service users. 


\section{LITERATURE/THEORETICAL FRAMEWORK}

This work was anchored on Systems Theory. A system may be seen as an ordered entity consisting of interconnected and interdependent units. It can also be described as an entity, which is an intelligible whole ( $\mathrm{Ng}$, Maull \& Yip, 2009), such that a boundary is perceived around it in order to differentiate internal and external elements in addition to identifying input and output that relate to and emerge from the entity (Mele, Pels \& Polese, 2010, p. 127). Systems theory (ST) therefore, is a theoretical perspective which analyses a phenomenon viewed holistically as opposed to simple summation of the elementary parts. According to Mele et al (2010), the focal point is on the inter-connections and relationships existing between parts so as to understand an entity's organization, functioning and outcomes. According to them, this view point implies a discourse between the duo of holism and reductionism. The systems idea has grown to become a generic concept applicable to every discipline such that almost anything now can be viewed as system. According to Charlton and Andras (2003, p. 12), ST is a large, complex, philosophical and empirical field; having several variants that emphasize different aspects. Consequently, differing perspectives of ST exist in the natural, physical, biological, social, management, information, technological, service, engineering, etc. disciplines. In a bid to unify the different perspectives into one coherent whole, von Bertalanffy (1968) came up with the concept of the General Systems Theory (GST) which is about generally applicable concepts and principles, as opposed to those applicable to a singular knowledge domain. The application of systems theory to management is usually not done with a straitjacket approach or mentality because of Charlton and Andras postulation above. Philosophically, social systems theory (Luhman, 1995) does not conform to any of the standard philosophical positions such as empiricism or idealism; but it is closely associated with pragmatism (Charlton \& Andras, 2003). This means that when it comes to systems theory especially the social systems variant, there are no absolute epistemological evaluations; rather what is obtainable is comparative evaluations with reference to practice. Thus, scholars (Charlton \& Andras, 2003; Luhman, 1995; von Bertalanfy, 1968) agree that when it comes to knowledge especially in the systems domain, there is no knowledge that is of absolute timeless truth. Hence, scholars are free to pragmatically adapt the theory to suit their discourse. In applying the systems thinking to this study, the authors focused on reliability, flexibility, efficiency and privacy (as components of SysQ) in relation to ES; underscoring the holistic perspective.

\section{The Concept of System Quality (SysQ)}

System Quality (SysQ) reflects the service users' perceptions about the technical level of communication (Akter et al, 2016; Delone, 2003; Xu et al, 2013). For this study's purpose, it is regarded as the system users' perceptions of the technical level of a service delivery system in the tourist site. Such systems might include information and communication technology (ICT) systems, relaxation facilities, work-out facilities, accommodation / hotel facilities etc. The identified sub-dimensions include system reliability, system efficiency, system flexibility and system privacy (Akter et al, 2016; Delone, 2003; Nelson et al, 2005; Parasuraman, 2005). System reliability is an indication of the extent to which the system is dependable over time (Delone, 2013; Liu \& Amett, 2000; Parasuraman et al, 2005) in delivering what it promises to deliver. In other words, given a time frame, will the system be as useful as it used to be? Will it deliver the same level of quality service it used to deliver? System efficiency is a reflexion 
of the ease of use of a system. In other words, it indicates the extent to which the service system (SS) is easy to use (Parasuraman, et al, 2005) by any given user. System flexibility measures the extent to which the SS is adaptable to different user needs and changing service conditions (Akter et al, 2016; Delone, 2003; Nelson et al, 2005; Parasuraman, 2005). The last subdimension System privacy reflects the extent to which the SS protects the privacy of the patient's health information (Akter et al, 2016; Parasuraman, 2005); but has been adapted for this study to mean a reflection of the extent to which the SS provides some level of confidentiality to the user who so desires.

\section{The Concept of Economic Sustainability}

The utilization of economic tools by early theorists helped them to aver that environmental protection policies could also promote innovation and turn in profit. Arthur Pigou in 1920 observed that the presence of incidental and uncharged services act as a hindrance to the achievement of market equilibrium. In his work "The Economics of Welfare", Pigou observed that the difference between marginal private costs and benefits as well as marginal social costs and benefits create "externalities" (Pigou, 1920). These externalities are conceived as transaction spill-overs, or costs and benefits unaccounted for in the given price of a good or service. In order to correct the market failure, Pigou proposed a tax on those activities that produce negative externalities at a rate equal to those external costs. By levying this Pigouvian tax, the market price will more accurately be a reflection of the comprehensive benefits and costs of the activity. Based on this, Michael Porter and Claas van der Linde theorized that pollution is a sign of inefficient use of resources. Therefore, reduction in pollution in production processes can be used to achieve win-win opportunities for the environment and economy (Porter \& van der Linde, 1995). These authors argued that competitive advantages depend on the innovation capacity; hence, competitiveness can actually be enhanced by stimulating innovative and strict environmental regulations (Porter \& van der Linde, 1995, p. 98). As stated by the the Porter's Hypothesis, introduction of new technologies and reduction of production waste can be encouraged through properly designed environmental policies that make use of market incentives. Testing these theories has yielded mixed results; nevertheless, it has been agreed by scholars that policy design and public support are essential elements for the success of these incentives. These notwithstanding, traditional command and control policies are generally regarded as less more business friendly than market-based environmental tools (Cooper \& Vargas, 2004).

The economic approach to thinking about sustainability has been summarized in a number of sources including Pezzey and Toman (2005) and Hamilton and Atkinson (2006). Early contributions to the contemporary literature such as Pearce and Atkinson (1993) employed basic intuitions concerning assets and sustainability but owed much to theoretical contributions by, scholars like Solow (1986) and Repetto et al (1989) who were credited with the pioneering study on asset accounting. It was argued in these contributions that sustainability can be equated to the non-declining values of all assets inclusive of natural resources. The implication of this conceptualization is that changes in asset values, measured by the net saving, is an indication of whether the economy is on a sustainable path or not. Soon afterwards, Hamilton (1994) coined the expression 'genuine savings' and it is this terminology that is now widely used, to describe this indicator. Subsequent research has refined the theory of economic sustainability and placed this formal analysis more clearly within a lineage of economic thought dating back not just to Hicks (1946) but before that to Fisher (1906) and after that Samuelson 
(1961). While these recent contributions differ in their exact details, they share general precepts in using growth theory to firmly establish the linkage between (net) savings, social well-being and sustainable development (e.g. Hamilton \& Clemens 1999; Dasgupta \& Mäler, 2000; Asheim \& Weitzman, 2001; Hamilton \& Hartwick, 2005; Hamilton \& Withagen, 2007).

The intuition of these theoretical contributions is straightforward enough. Total wealth is typically conceived as the value of all assets in an economy. To measure sustainability, it is important that wealth measurement spans as wide a range of assets as possible, including assets with negative shadow prices such as pollution stocks. It is this wealth that is the basis of future well-being: that is, the greater the (real) value of current wealth, the greater the level of wellbeing that can be sustained into the future. It stands to reason, therefore, that current changes in wealth must have consequences for future well-being. For example, if a decline in wealth now leads to falls in future levels of well-being then this economy would not be sustainable (Pezzey, 1989). This indicator is currently being described as adjusted net savings by the World Bank. In fact, there are two sides to the wealth coin. When economists talk about wealth they are typically referring to social welfare. This is defined as the present value of consumption: that is, the discounted stream of consumption now and in the future. This consumption is construed broadly given that it derives not just from the enjoyment of material goods and services but also amenities and so on provided by the environment. However, if wealth can also be measured by the value of assets then tracking changes in assets, in the here and now, tells us something about what is happening to social welfare. It follows that changes in wealth give us clues about changes in social welfare (i.e. well-being in the future) and sustainability.

Hence, Hamilton and Clemens (1999) demonstrate that genuine savings which is defined as change in real asset value is equal to change in social welfare. In other words, genuine savings provide a signal about the direction (and magnitude) of change in total (or comprehensive) wealth. Hamilton and Clemens further posited that negative genuine saving levels must imply that future levels of well-being over some period of time are lower than current levels. In other words, negative genuine saving simply indicates unsustainability. This particular finding is obtained by looking at the optimal development path for an economy. Of course, 'real world' economies are not optimal and, indeed, much of modern environmental and resource economics is premised on exactly this observation. Where does this leave conclusions about the measurement of sustainability and future well-being? Contributions from Dasgupta and Mäler (2000), and Hamilton and Withagen (2007) have all relaxed the assumption of optimality in looking at the link between saving and sustainability. In doing so, it has been shown that even in non-optimal economies genuine saving is still an indicator of changes in development prospects. Pezzey (2004) makes the point that genuine saving provides a one-sided sustainability test: if saving is negative, then there must be future declines in well-being. The opposite is not true in general: positive saving at a single point in time does not indicate necessarily that future well-being is everywhere non-declining. However, this is not the end of the story as at least two papers, looking at general policy prescriptions that will ensure economic sustainability, have found. Thus, Hamilton et al. (2006) and Hamilton and Withagen (2007) show that positive genuine saving does indicate that development is sustainable so long as it is always both positive and constant either in terms of its rate (i.e. as a proportion of output) (Hamilton \& Withagen, 2007) or its level (i.e. money value) (Hamilton et al. 2006). In both cases, it has been theoretically shown that following any such rule can lead to increasing wellbeing over time. Put this way, the Hartwick rule (Hartwick, 1977) where genuine saving is 
equal to zero at each point in time in the future ensuring that well-being will be constant, is thus just one sustainability rule a government might adopt.

\section{System Quality (SysQ) and Economic Sustainability (ES)}

In their study, "Sustainability of three apple production system" conducted in Washington State, United States of America, Reganold, Glover, Andrews and Hinman (2001) established that system quality as manifested in organic farming system significantly relates to economic sustainability; by producing apples that are sweeter and less tart, thereby yielding greater profitability as well as better energy efficiency. Similarly, Akter et al (2016) in their study "Enabling a transformative service system by modelling quality dynamics" which focused on health care delivery system used a sample size of 311 respondents and the partial least square path modelling (PLS-PM) analysis technique to find that the quality of service systems significantly and positively impacts on satisfaction $(\beta=0.394, p<0.05)$, value $(\beta=0.799, p<$ $0.05)$, and continuance $(\beta=0.1444, p<0.05)$. These measures of theirs are reflective of the economic dimension because a satisfied customer is one that values the service he has received and is willing to continue using the service. This implies economic benefits to the service providing entity. It is understandable that Akter et al are careful with their choice of words as ethics of the medical profession precludes the use of terms that connote economic benefits like business growth and profitability. On their path, Al-Mamary, Shamsuddin and Aziati (2014) in their study "The relationship between system quality, information quality and organizational performance" affirmed that system quality significantly impacts on organization's performance through the acceptance of the system's efficiency and effectiveness; thus leading to economic sustainability. Relatedly, Sousa and Cauchick-Miguel (2015) used their study "Product-service systems as a promising approach to sustainability: Exploring the sustainable aspects of a PSS in Brazil" (which focused on improving the quality of a Brazilian tourist site's product service system (PSS) as a means of achieving economic sustainability) to find that the PSS generates economic gains to the concerned stakeholders. Their result which was based on a qualitative data analysis indicated that consumers gained in the price as the PSS water sold for US\$1.65 per 20 litres; while traditional bottled water of similar volume sold for US\$ 4.15. The business establishments equally gained in that the PSS under study added value to the businesses and provided monetary benefits with significantly low operational costs which helped the businesses to save $25 \%$ profit on sales. Moreover, a number of customers began shopping and patronizing the establishments in a more frequent manner due to the PSS there; so that opportunity exists for the businesses to improve on their sales of other products/services. On the part of the company, they also benefited in that according to the information they provided, their operational costs became low, allowing for a high profit margin. Thus, a quality PSS relates positively to economic sustainability (ES). Other studies of similar conclusions include Choi et al, (2004); Athanassopoulos (2000); Alter (2012); Cronin et al (1997).

On the contrary, these economic benefits are not automatic as observed by Shostack (1985). She argued that service systems in themselves do not yield economic benefits; rather it is the integration of resources in a service system that together with prevailing economic situation and managerial prowess that guarantees significant financial returns to organizations. This means that quality systems alone are not enough to generate economic benefits; rather they are necessary conditions for significant economic benefits to be realized. Building on these, the researchers hypothesized that there is no significant relationship between the dimensions of 
system quality and the economic sustainability of Nigerian tourist sites. Specifically, it was hypothesized that:

$\boldsymbol{H}_{0: 1} 1$ There is no significant relationship between system reliability and ES.

$\boldsymbol{H}_{0: 2}$ There is no significant relationship between system efficiency and ES.

$\boldsymbol{H}_{0: 3}$ There is no significant relationship between system flexibility and ES.

$\boldsymbol{H}_{0: 4}$ There is no significant relationship between system privacy and ES.

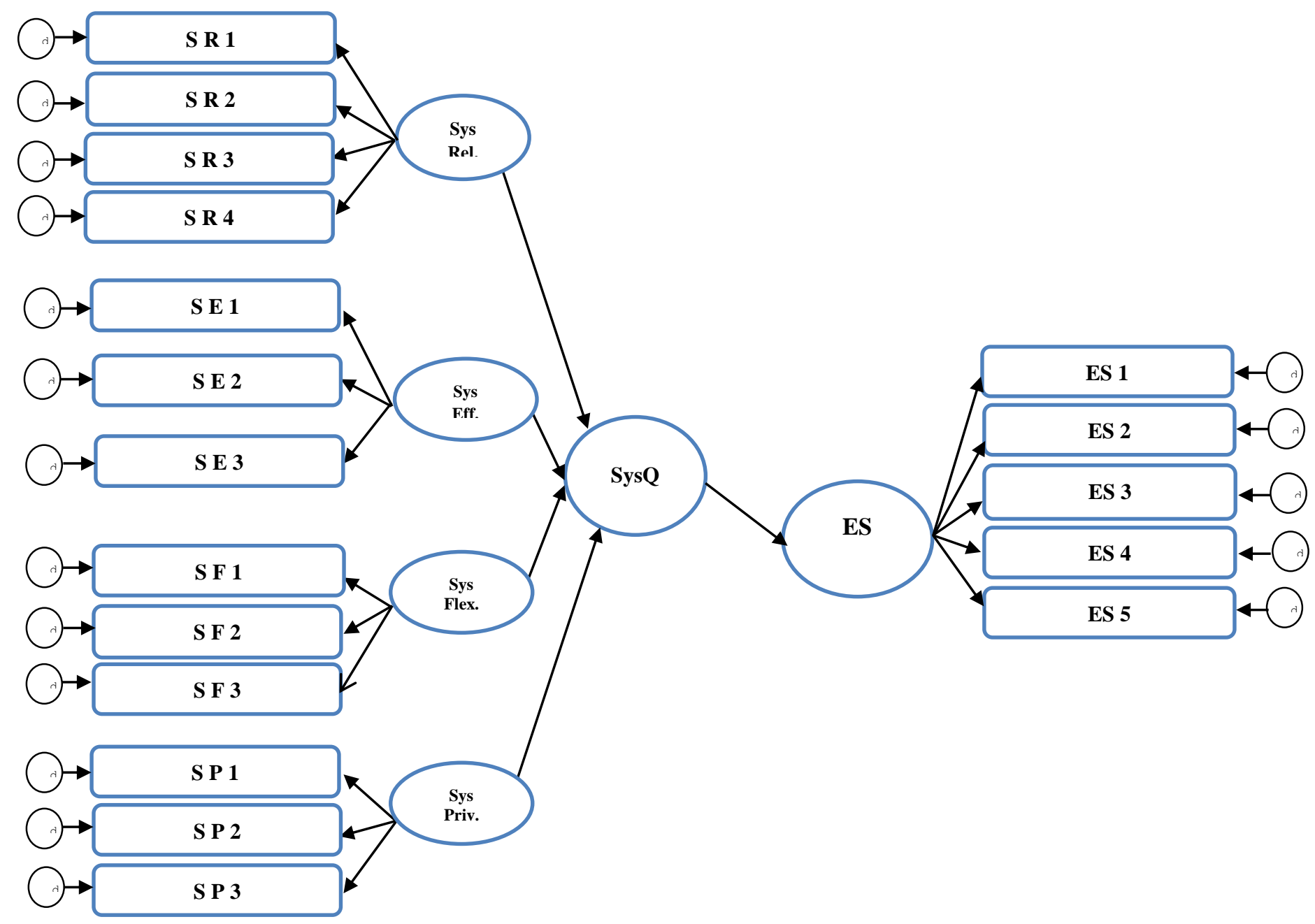

Figure 2: Operational Framework of the Study Variables

Source: Researchers Conceptualization, 2019

\section{METHODOLOGY}

This study adopted the cross-sectional survey method on the basis that the research involved selecting samples of elements from the population of interest measurable at a single point in time (Malcolm 2003; Baridam 2001). More so, it was adopted because it enables researchers have access to direct information by gathering data from primary sources which enhances the measurement of the dependent and independent variables; saves time, as well as provide a wider representation of a large target population (Creswell, 2014; Miles \& Huberman, 1994; Silverman, 2013; University of Southern Califonia Libraries, 2016). 
The population of this study comprised major tourist sites in Nigeria. However, before arriving at this number, basic information about the population is deemed necessary. The country comprises 36 federating states divided into six geopolitical zones - North East, North West, North Central, South East, South West and South-South. Data on the number of tourist sites in Nigeria are varied and conflicting. However, the data provided in Ayodele (2017) which puts the number at two hundred and forty-nine - 249 is so far, the most comprehensive; and was adopted by the researcher as the population of the study. Consequently, the population of this study consists of the two hundred and forty-nine tourist sites in Nigeria. Due to the scope and nature of the research, the accessible population was streamlined to capture tourist sites in the South-South and South-East geo-political zones of Nigeria where the study was focused. According to Ayodele (2017), tourist sites in these two regions boast of a total number of sixty with the exception of eleven non-functional sites which brought it down to forty-nine. However, the researcher added six newly established tourist sites in these regions which where not captured by Ayodele (2017); making the accessible population a total of fifty-five tourist sites. Since this number is relatively small, all of them were considered as the sample size. The sample elements therefore, comprised the managers and assistant managers of these tourist sites as well as the proportion of visitors and residents that were considered for the study. The manager and his assistant made it two from each of these tourist sites, totalling one hundred and ten. Furthermore, to capture the visitors and residents' component of the sample size, the Cochran's (1977) formula for sample size determination for an infinite population was utilized. This gave rise to a sample of 275 visitors / residents; bringing the total sample to 385 . The purposive sampling technique was used to select the managers and assistant managers; while the opportunistic sampling technique was used to select the visitors / residents. Data were collected through a questionnaire administered by the researchers. This was corroborated with tourist site records / archives; as well as information from consulted journals, textbooks, and internet materials. The validity and reliability of the instrument were established through confirmatory factor (CFA) as shown in the analysis section. Univariate analysis was carried out using mean and standard deviation techniques; while bivariate and further analyses were performed using Structural Equation Modelling (SEM) with the aid of IBM SPSS software, version 21.0 .

\section{Results/Findings}

The analyses were based on the 385 copies of the questionnaire administered. Only 362 (94\%) copies of this were retrieved; out of which 328 copies were rightly filled and found useable for the study. Thus, the useable response rate is $85.20 \%$. For the univariate analyses, the researchers relied on Asawo (2009), who classified mean returns as 1.0 - 2.0 (low), 2.1 - 2.8 (moderate), 2.9 - 3.5 (high) and above 3.5 (very high); to set the threshold for accepting the applicability of the constructs and their items at mean $(\boldsymbol{M})$ value of 2.5. 


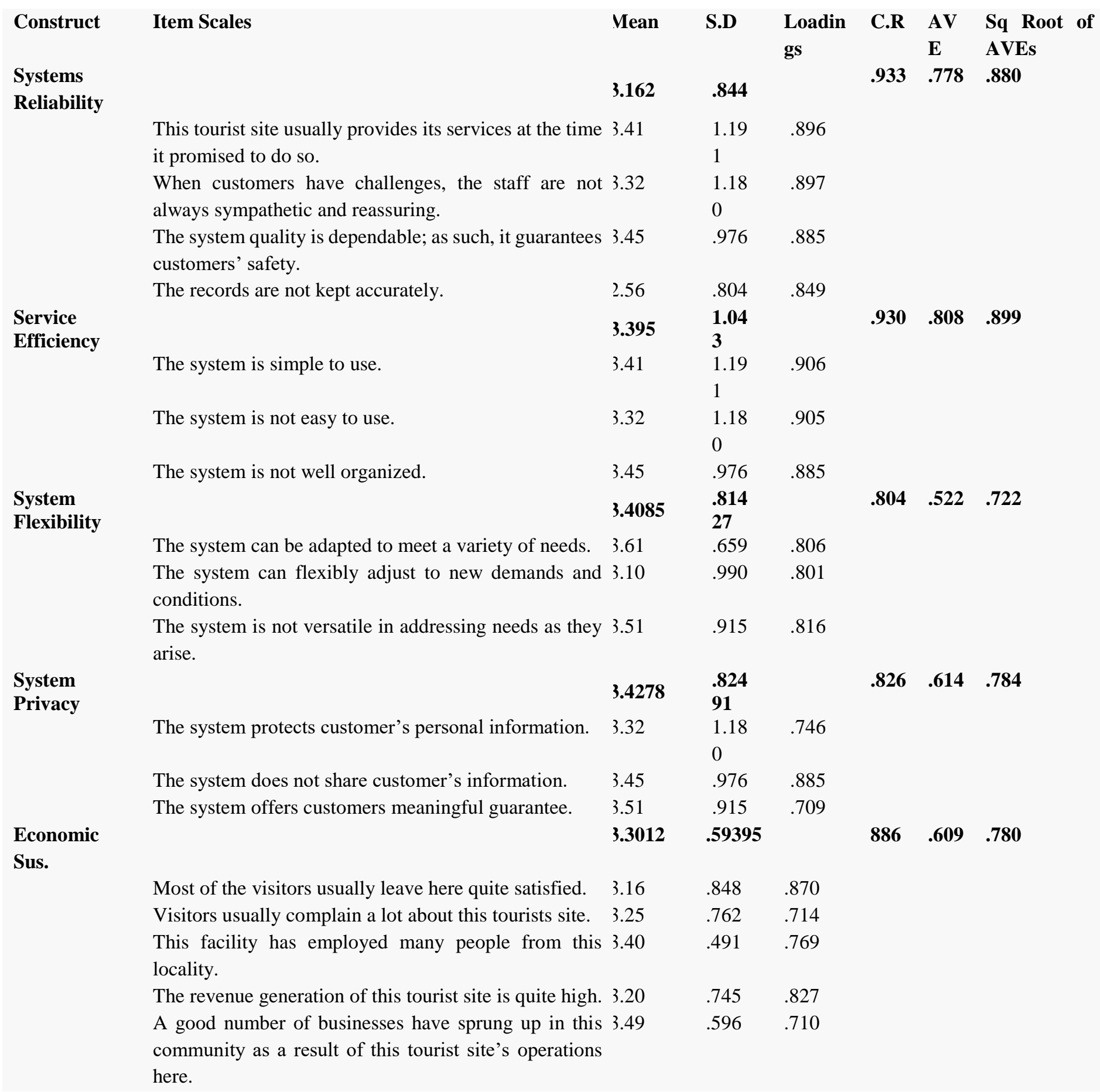

\section{Table 1: Descriptive Statistics and Assessment of First Order Reflective Model of the} Constructs

Source: Extract from SPSS Output Based on Analysis, 2019

Table 1 shows the descriptive statistics and assessment of the first-order reflective model of the constructs. The descriptive statistics shows the mean and standard deviation for each of the constructs as well as that for their respective indicators. Apart from indicator number 4 of systems reliability which reported a mean of 2.56 , all the constructs and their indicators reported high mean values indicating their applicability in the study. Furthermore, the table 
shows the assessment of the measurement model of the constructs; using the CFA to substantiate the convergent and discriminant validities. This helped to confirm the relationship between the measurement variables and the latent variables. From the table, it could be seen that the factor loadings for all the indicators exceeded the threshold of 0.5 and were significant at $\mathrm{p}<0.05$. This means that the items related well to their constructs thus affirming the convergent validity. The reliability was established using the composite reliability (CR) values which reported high values $(.933, .930, .804, .826$ and .886$)$ for system reliability, system efficiency, system flexibility, system privacy and economic sustainability respectively. Similarly, the average variance extracted (AVE) reported acceptable values $(.778, .808, .522$, .614 and .609) respectively. Both the CR and AVE values were greater than the threshold marks for a satisfactory measurement model (AVE>.50 and $\mathrm{CR}>.80$ ) as prescribed by Bagozzi and Yi (2012).

\begin{tabular}{|c|c|c|c|c|c|c|}
\hline CONSTRUCT & & SYR & SYE & SYF & SYP & $\begin{array}{l}\text { ECO } \\
\text { SUS }\end{array}$ \\
\hline System Reliability (SYR) & & .880 & & & & \\
\hline System Efficiency (SYE) & & .653 & .899 & & & \\
\hline System Flexibility (SYF) & & .383 & .397 & .722 & & \\
\hline System Privacy (SYP) & & .488 & .321 & .693 & .784 & \\
\hline $\begin{array}{l}\text { Economic Sustainability } \\
\text { Sus) }\end{array}$ & (Eco & .686 & .695 & .444 & .620 & .780 \\
\hline
\end{tabular}

\section{Table 2: Correlation Matrix}

*The square root of the AVEs on the diagonal

Source: Extract from SPSS Output Based on Analysis, 2018

Table 2 shows the correlation matrix of the constructs, with the square root of the AVEs shown on the diagonal. From the cross-loadings, it could be seen that the items have stronger relationships with their own constructs than that of others. Furthermore, the square root of the AVEs on the diagonal are greater than their associated correlations ( $\mathrm{AVE}>$ correlations), indicating that the constructs do not share similar items but are rather distinct from each other; thus confirming discriminant validity. Therefore, the first order measurement model was confirmed satisfactory and employed for testing the higher order measurement model as well as the structural model as shown in subsequent sections.

\section{Additional Analysis}

To further establish the model fit of the study, other parameter estimates on goodness of fit where carried out. The outcome of these analyses has been shown on table 3 . 
Table 3: Other Parameter Estimates for Goodness of Fit

\begin{tabular}{ll}
\hline $\begin{array}{l}\text { Goodness of fit } \\
\text { Parameter Estimates }\end{array}$ & Result \\
\hline Chi-Square $\mathbf{X}^{\mathbf{2}}$ & $\mathrm{X}^{2}(5)=6.072, \quad \mathrm{P}=$ \\
& 0.000 \\
CFI & $\mathrm{CFI}=0.994$ \\
GFI & $\mathrm{GFI}=0.989$ \\
AGFI & $\mathrm{AGFI}=0.968$ \\
TLI & $\mathrm{TLI}=0.988$ \\
RMSEA & $\mathrm{RMSEA}=0.06$ \\
SRMR & SRMR $=0.022$ \\
\hline Source: Extract from SPSS Output Based on Analysis, 2018
\end{tabular}

From table 3, the Chi square $\left(\chi^{2}\right)$ which is the most common test for goodness of fit estimates the magnitude of discrepancy between the observed and estimated covariance. The result showed a $\chi^{2}$ value of 6.072 with a degree of freedom (d f) of 5, at the 0.05 level of significance. This indicates that the model is fit as it gave a satisfactory p-value of 0.000 ; which is significant at the 0.05 level. However, due to the sensitivity of Chi square to sample size (Bagozi \& Yi, 2012), other indexes were explored to establish the model's practical fit. These include comparative fit index (CFI) which is an indicator of relative non-centrality estimate for independence model discrepancy. This analysis showed a value of 0.994 which is satisfactory as the satisfactory range of the estimate is between 0 - 1 . In fact, the result shows a better fit due to its closeness to 1 (Bagozi \& Yi, 2012; Cao, Mokhtarian \& Handt, 2007). The table also shows a goodness of fit index (GFI) value of 0.989 which indicates a better fit as the threshold ranges between 0 and 1 (Chou \& Kim, 2009; Wallgren \& Hanse, 2007; Parra et al., 2006). The adjusted goodness of fit index (AGFI) which is a further purification of the GFI gave a value of 0.968 which is also a good report as the threshold is between 0 and 1; and the higher the better (Chou \& Kim, 2009; Wallgren \& Hanse, 2007; Parra et al., 2006). The Tucker and Lewis index TLI (also known as non-normed fit index NNFI) showed a value of 0.988 which is also proved satisfactory by (Bagozi \& Yi, 2012; Chou \& Kim, 2009; Cao et al, 2007) who confirmed a threshold of between $0.00-1.00$. The root mean square error approximation (RMSEA) gave a value of 0.06 which satisfied the threshold of $\leq 0.06$. also the SRMR (Standardized Root Mean Square Residual) showed a value of 0.022 which also satisfied the threshold condition of $\leq .08$. Based on these additional parameter estimates, the study submitted that the constructs are of a good model fit. 
Structural Model and Findings

The structural model shows the result that emanated from the test of hypothesis.

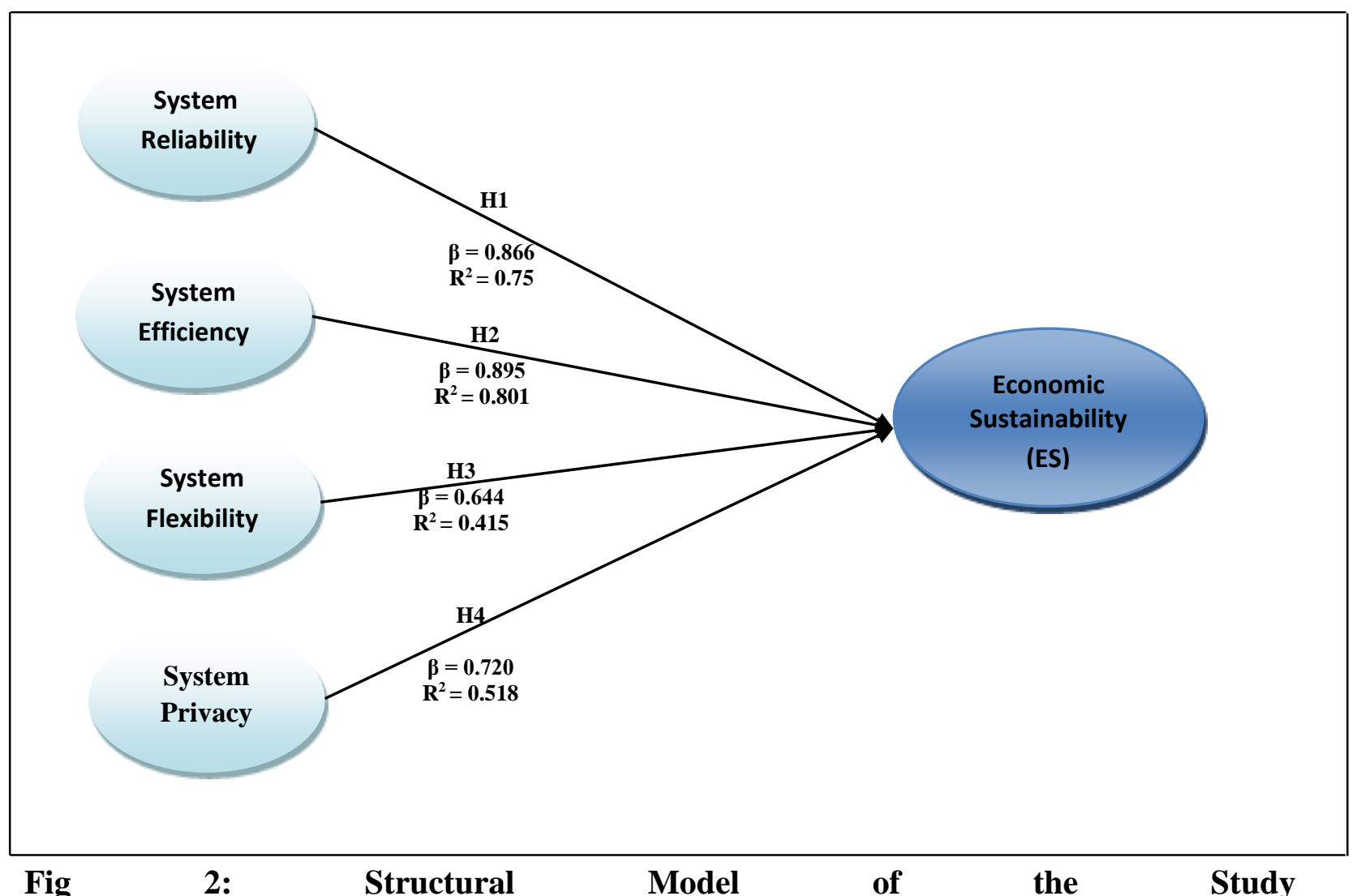

Source: Survey Report based on SPSS Output, 2018.

\section{Interpretation of Structural Model Result}

Figure 2 shows the result of the hypotheses testing. The first result from the first hypothesis boasts of a standardized beta $(\beta)$ of 0.866 at a 0.05 level of significance. This shows that there is a strong positive and significant relationship between system reliability and ES. This implies that system reliability is a strong predictor of ES in the Nigerian tourist sites. However, the $\mathrm{R}^{2}$ value of 0.750 reveals that system reliability can predict ES only to the tune of $75 \%$ leaving the remaining $25 \%$ to other factors not captured in the model. The second result which emanated from hypothesis two indicated a standardized beta $(\beta)$ value of 0.895 at 0.05 level of significance, which connotes that there is a strong direct significant relationship between system efficiency and ES. This implies that system reliability is a strong antecedent of economic sustainability. However, the $\mathrm{R}^{2}$ value of 0.801 reveals that system efficiency can predict ES only to the tune of $80.1 \%$ leaving the remaining $19.9 \%$ to other factors not captured in the model. The third result which originated from hypothesis three reported a standardized beta $(\beta)$ value of 0.644 at the 0.05 level of significance. This connotes the existence of a strong direct relationship between system flexibility and ES. The $\mathrm{R}^{2}$ value of 0.415 reveals that system flexibility can be used to explain the variance in ES only to the tune of $41.5 \%$ leaving the remaining $58.5 \%$ to other exogenous factors not accommodated in the model. Lastly, the fourth result emanated from hypothesis four, with a standardized beta $(\beta)$ value of 0.720 at 0.05 level of significance. This shows that there is a strong significant relationship between system flexibility and economic sustainability of tourist sites in Nigeria., The $\mathrm{R}^{2}$ value of 0.518 as 
shown in the model summary indicates that system flexibility can explain the variance in ES to the tune of $51.8 \%$ leaving the remaining $48.1 \%$ to exogenous factors not included in the model. These results are further elucidated in the structural path model shown in table 4.

$\begin{array}{llll}\text { Structural Model } & \text { Path Coefficient } & \text { Standard Error } & \text { t Statistic } \\ \text { Sys. Rel. } \rightarrow \text { E S } & 0.866 & 0.093 & 19.128 \\ \text { Sys. Eff. } \rightarrow \text { E S } & 0.895 & 0.080 & 24.309 \\ \text { Sys. Flex. } \rightarrow \text { E S } & 0.644 & 0.127 & 17.321 \\ \text { Sys Priv. } \rightarrow \text { E S } & 0.720 & 0.110 & 16.058\end{array}$

Table 4: Structural Path Modelling

Source: Extract from SPSS Output Based on Analysis, 2018

\section{Interpretation of the Structural Path Model}

Table 4 shows the structural path model of the study, which confirmed that there is a direct and significant relationship between the dimensions of SysQ and ES. The strongest path being the "Sys. Eff. $\rightarrow$ ES" path with a beta value of 0.895 and standard error of 0.080 ; while the weakest path is the "Sys. Flex. $\rightarrow$ ES" path with a $\beta$ value of 0.644 and standard error of 0.127 . Furthermore, with the standard error values of 0.093, 0.080, 0.127 and 0.110 (respectively), which are minimal, the results are properly spread. Thus it shows that the sample for this study accurately represents the entire population (Dauglas \& Marting, 2005; Mary, 2008).

\section{DISCUSSION}

The results of the analyses on the hypotheses indicated that there is significant direct relationship between the dimensions of system quality and ES. This is not surprising at all as support for it was found in the works of Reganold et al (2001) who established a significant relationship between system quality as manifested in organic farming system and ES. Their study implied that a system with the desired quality will normally lead to sustainable economic gains; thereby affirming the position of this study that acceptable systems quality usually engenders sustainable economic benefits such as improved revenue, employment generation and business opportunities. Akter et al (2016) also affirmed this finding when they established that the quality of service systems significantly and positively impacts on satisfaction, value and continuance in health care delivery system, which are reflective of their economic sustainability. Also supportive of this finding is the work of Al-Mamary, Shamsuddin and Aziati (2014) who used their study on the relationship between system quality, information quality and organizational performance to affirm that system quality significantly impacts on organization's performance through the acceptance of the system's efficiency and effectiveness; thus leading to economic sustainability. This means that the acceptance of the quality offerings of a system will most likely lead to ES. Another very supportive study is that of Sousa and Cauchick-Miguel (2015) who used their study to corroborate that the quality of a system (in this case, a product-service system) can be used to achieve economic sustainability by generating economic gains to the concerned stakeholders. In other words, a quality PSS relates positively to ES. Other corroborative studies include Alter (2012); Athanassopoulos (2000); Choi et al, (2004); Cronin et al (1997). 
Contrariwise, Shostack (1985) appeared to have disagreed with this finding when she argued that economic benefits are not automatic as service systems in themselves do not yield economic benefits; rather it is the integration of resources in a service system that together with prevailing economic situation and managerial prowess that guarantees significant financial returns to organizations. This means that quality systems alone are not enough to generate ES; rather they are necessary conditions for significant economic benefits to be realized. This seeming contrary opinion is understandable as SysQ on its own lacks the capacity to engender ES. Rather it is the efficient and effective integration of the resources of the system in a cocreation manner that can guarantee the desired ES. Nevertheless, it should be understood that the system concept in the "SysQ" construct implies an integrated approach; covering both the human, material, technological and co-creation aspects of the system quality.

\section{Implication to Research and Practice}

The implication of this study is that quality systems can be relied upon to engender economic sustainability in the Nigerian tourist sites. Hence, application of the following propositions would help assuage the operations management challenges in the Nigerian tourist sites.

1. Tourist site owners and most importantly, the operations managers should endeavor to design their facilities in such a way that the system can be relied upon for quality output to customers. This can be achieved by instituting and implementing continuous improvement programs (such as training and re-training of personnel, system redesigning cum updating, benchmarking and peer-reviewing, integrated approaches to system design such as value co-creation with visitors and residents) that can help the system operate with global best practice and remain competitive enough to attract the needed ES.

2. They should explore means of cutting down cost while improving on quality output. This will help to guarantee efficient system operations. Techniques like Nano Technology, Total Quality Management (TQM), Just in Time (JIT), Reverse Engineering, Outsourcing, Public Private Partnerships (PPP), Privatization and Commercialization etc., can be used to achieve this purpose.

3. They should ensure that the system is designed and/or re-designed in such a way that it is can adapt to changing demands and technological improvements/innovations. This will help sustain the attractiveness of the site and avoid the moribund nature and abandonment syndrome plaguing a good number of tourist sites in Nigeria. The services of systems experts and tourism professionals can be sought and regularly engaged to achieve this purpose.

4. Features that can help to ensure safety, personalized needs, spirituality, environmental friendliness etc., must be consciously incorporated into the design of such tourist facilities. This will help keep them abreast with modern day tourist facilities requirement needed to guarantee continued patronage and ES.

\section{CONCLUSION}

This study sought to ascertain the relationship between SysQ (as dimensioned by system reliability, system efficiency, system flexibility) and ES. The purpose was to establish if each of these dimensions had a significant relationship with ES; giving rise to four hypotheses. The problem of the study stemmed from the fact that most tourist sites in Nigeria are not 
economically sustainable as they still rely on government grants to function; and where such is not forth-coming for obvious reasons which may be political or otherwise, the operations managers operate at a loss and in extreme cases such tourist sites become moribund leaving no future for coming generations; with means of livelihood and economic benefits lost. This seem to have plagued most Nigerian tourist sites. The study adopted a survey design with a sample of 328 drawn from a sample size of 55 tourist sites in the South-South and South-East zones of Nigeria; cutting across tourist site operations managers cum their assistants, as well as tourist site visitors and residents. The purposive and accidental sampling techniques were used in selecting these samples. Data were generated trough a partially adapted instrument which was validated and tested for reliability via the CFA method; which showed acceptable levels of convergent and discriminant validities as well as high levels of reliability. The analyses were carried out using mean and standard deviation techniques; as well as the SEM techniques. The results showed good model fit for the measurement models and significant direct relationships for the structural models. These results were extensively discussed in line with previous findings of similar studies. Consequently, the study concluded that SysQ is an antecedent of ES; and that the dimensions of SysQ are good predictors of ES; and can be used to explain the variance in ES to the tunes of $75 \%$ for system reliability, $80 \%$ for system efficiency, $41.5 \%$ for system flexibility and $52 \%$ for system privacy, leaving the rest to exogenous factors not accounted for in the model. This implies that operations managers need to effectively control these factors for them to realize improved variance explanatory power of these antecedents.

\section{Future Research}

This study focused only on system quality and economic sustainability; leaving other aspects of service systems quality and sustainable tourism development (STD) untouched. Hence interested investigators can consider the following for future research: System Quality and Socio-cultural sustainability; System Quality and Environmental Sustainability; Service Quality and Economic Sustainability; Service Quality and Socio-cultural Sustainability; Service Quality and Environmental Sustainability; Information Quality and any of the measures of STD etc. Any of these suggestions can also be investigated using industries and geographic locations other than that used for this study.

\section{References}

Adora, C. U. (2010). Managing tourism in Nigeria: The security option. Management Science and Engineering, 4(1), 2010, 14-25.

Al-Ababneh, M. M. (2017). Service quality in the hospitality industry. Journal of Tourism and Hospitality, 6. doi: 10.4172/2167-0269.1000e133

Athanassopoulos, A. D. (2000). Customer satisfaction cues to support market segmentation and explain switching behavior. Journal of Business Research, 47, 191-207. Retrieved from http://refhub.elsevier.com/S0925-5273(16)30219-5/sbref9

Atkinson, G. (2008). Ground-motion prediction equations for eastern North America from a referenced empirical approach: Implications for epistemic uncertainty. Bulletin of the Seismological Society of America, 98, 1304-1318.

Alter, S. (2012). Challenges of service science. Journal of Information Technology Theory and Application, 13(2), 22. Retrieved from www.usfca.edu

Akter, S., Wamba, S. F., \& D'Ambra, J. (2016). Enabling a transformative service system by modelling quality dynamics. International Journal of Production Economics. Retrieved from http://dx.doi.org/10.1016/j.ijpe.2016.08.025 Al-Ababneh, M. M. 
(2014). Classifying Jordanian hotels based on their TQM implementation. Dirasat Administrative Science, 41(2), 482-496.

Andreassen, T. W., Kristensson, P., Lervik-Olsen, L., Parasuraman, A., McColl-Kennedy, J. R., Edvardsson, B., \& Colurcio, M. (2016). Linking service design to value creation and service research. Journal of Service Management, 27(1), 21-29. DOI https://doi.org/10.1108/JOSM-04-2015-0123Awunor, A. (2017). Dwindling domestic tourism: Causes and impacts. Nigeria Today. Retrieved May $20^{\text {th }}$ from http://wwwnigeriatoday.ng

Asheim, G. B., \& Weitzman, M. L. (2001). Does NNP growth indicate welfare improvement? Economics Letters, 73, 233-239.

Ayeni, D. A., \& Ebohon, O. J. (2013). Exploring sustainable tourism in Nigeria for developmental growth. European Scientific Journal, 8(20), 126 - 140.

Ayodele, I. A. (2017). Tourism: Gateway to good health and good life. An inaugural lecture delivered at the University of Ibadan on $12^{\text {th }}$ of October 2017. Ibadan, Nigeria: Ibadan University press.

Bagozzi, R. P., \& Yi, Y. (2012). Specification, evaluation and interpretation of structural equation models. Journal of the Academy of Marketing Science. Doi: 10.1007/s11747011-0278-X

Baridam, D. M. (2001). Research methods in administrative science (3rd ed.). sherbrook association

Cao, X., Mokhtarian, P. L., \& Handy, S. L. (2007). Do changes in neighbourhood characteristics lead to changes in travel behaviour? A structural equations modelling approach. Transportation, 34, 535-556.

Charlton, B. G., \& Andras, P. (2003). What is management and what do managers do? A systems theory account. Philosophy of Management, 3, 1-15.

Chinjavata, W., Lubbe, S., \& Klopper, R. (2015). Evaluation of information system service quality in a South African governmental department. Alternation, 22(1), 289-326.

Choi, K. S., Cho, W. H., Lee, S., Lee, H., \& Kim, C. (2004). The relationships among quality, value, satisfaction and behavioral intention in health care provider choice: A South Korean study. Journal of Business Research, 57, 913-921. Retrieved from http://refhub.elsevier.com/S0925-5273(16)30219-5/sbref33

Chou, J., Kim, C., Tsai, P., Yeh, C. \& Son, H. (2017). Longitudinal assessment of higher-speed rail services delivery satisfaction and operations: A case study of Taiwan and Korean system. KSCE Journal of Civil Engineering, 21(6), 2413-2428. Doi: https://doi.org/10.007/s12205-017-1140-6

Chou, J. S., \& Kim, C. (2009). A structural equation analysis of the QSL relationship with passenger riding experience on high speed rail: An empirical study of Taiwan and Korea. Expert Systems with Applications, 36(3, Part 2), 6945-6955.

Cooke, D. (2015). End cultural isolationism. Retrieved from http://www.roadside.org/endcultural-isolationism

Cooper, P. J., \& Vargas, M. (2004). Implementing sustainable development: From global policy to local action. Lanham, MD: Rowman and Littlefield Publishers Inc.

Creswell, J. W. (2014). Research design: Qualitative, Quantitative and Mixed Approaches (4th ed.). USA, Sage Publication Ltd.

Cronin, J. J., Brady, M. K., Brand, R. R., Hightower Jr, R., \& Shemwell, D. J. (1997). A crosssectional test of the effect and conceptualization of service value. Journal of Service 
Marketing, 11, 375-39. Retrieved from http://refhub.elsevier.com/S09255273(16)30219-5/sbref35

Dasgupta, P. (2000). Economic progress and the idea of social capital. In Dasgupta, P. \& Serageldin, I. (Eds.).Social capital: A multifaceted perspective.

Dauglas, G. M., \& Marting, J. B. (2005). Standard deviation and standards error. BMJ, 331(7521), 903. Doi: https://doi.org/10.1136/bmj-331-7521.903

Delone, W. H. (2003). The DeLone and McLean model of information systems success: A tenyear update. Journal of Management Information Systems, 19, 9-30. Retrieved from http://refhub.elsevier.com/S0925-5273(16)30219-5/sbref132c

Ekundayo, I. M., \& Abutu, G. N. (2015). Nigerian tourism: A catalyst for sustainable national development. International Journal of Public Administration and Management Research (IJPAMR), 3(1), 37-47.

Fisher, I. (1906). The nature of capital and income.

Haghkhah, A., Ebrahimpour, A., Abdul Hamid, A., \& Abdul-Rasid, S. Z. (2011). The Impact of Service Quality on Tourism Industry. Retrieved from https://www.researchgate.net/publication/206662601

Hamilton, K. (1994). Green adjustments to GDP. Resources Policy, 20(3), 155-168.

Hamilton, K., \& Atkinson, G. (2006). Wealth, welfare and sustainability advances in measuring sustainable development. Retrieved from http://dx.doi.org/10.4337/9781847202970.224

Hamilton, K., \& Bolt, K. (2004). Resource price trends and development prospects. Portuguese Economic Journal, 3, 85-97.

Hamilton, K., \& Clemens, M. (1999). Genuine saving in developing countries. World Bank Economic Review, 13(2), 333-356.

Hartwick, J. M. (1977). Intergenerational equity and the investing of rents from exhaustible resources. American Economic Review, 66, 972-974.

Hamilton, K., \& Hartwick, J. M. (2005). Investigating exhaustible resource rents and the path of consumption. Canadian Journal of Economics, 38(2), 615-621.

Hamilton, K., \& Withagen, C. (2007). Savings growth and the path to utility. Canadian Journal of Economic Review, 40(2), 703-713. Doi: https://dio.org.10.111/j.13652966.2007.00427.x

Heskett, J. L., Sasser, W. E., \& Schlesinger, L. A. (1997). The Service Profit Chain. New York, NY: The Free Press.

Hicks, J. R. (1946). Value and Capital (2nd ed.). Oxford: Clarendon Press.

Huber, G. P., \& Power, D. J., (1985). Retrospective reports of strategic level managers: Guidance for increasing their accuracy. Strategic Management Journal, 6(2), 171180. doi: https://doi.org/10.002/smj.4250060206

Luhman, N. (1984). Social system. Stanford University Press.

Liu, C., \& Arnett, K. P. (2000). Exploring the factors associated with web success in the context of electronic commerce. Information \& Management, 38(1), 23-33.

Malcolm, S. (2003). Research methods in accounting. London, Sage Publication.

Mary, L. M. (2008). Standard error: Meaning and interpretation. Biochemia Mdeica, 18(9), 713. Doi: https://doi.org/10.11613/bm

Mele, C., Pels, \& Polese, F. (2010). A brief review of systems theories and their managerial applications. Service Science, 2(1/2), $126-135$.

Nelson, R. R., Todd, P. A., \& Wixom, B. H. (2005). Antecedents of information and system quality: An empirical examination within the context of data warehousing. Journal of 
Management Information System, 21, 199-235. Retrieved from http://refhub.elsevier.com/S0925-5273(16)30219-5/sbref103

Ng, Irene, C. L., Roger, M., \& Nick, Y. (2009). Outcome-based contracts as a driver for systems thinking and service-dominant logic in service science: Evidence from the defence industry. European Management Journal, 27, 377-387.

Okpolo, A. I., \& Okpolo, U. P. (2002). Tourism in Nigeria. Nsukka: Afro Orbis Publishers Limited.

Parasuraman, A, Zeithaml, V., \& Berry, L. L. (2005). Alternative scales for measuring services and quality. Journal of Retailing, 70(1) 193-199.

Parasuraman, A., Zeithaml, V. A., \& Berry, L. L. (1985). A conceptual model of service quality and its implications for future research. Journal of Marketing, 49, 41-50.

Pearce, D. W., \& Atkinson, G. D. (1993). Capital theory and the measurement of sustainable development: An indicator of weak sustainability. Ecological Economics, 8(2), 103108.

Perera, P., \& Vlosky, R. (2013). How previous visits shape trip quality, perceived value, satisfaction, and future behavioral intentions: The case of forest-based ecotourism in Sri Lanka. International Journal of Sport Management, Recreation and Tourism, 11(1), 1-24

Pezzey, J. V. C., \& Toman, M. A. (2005). Sustainability and its economic interpretations. In Simpson, R. D., Toman, M. A., \& Robert, U. (Eds.). Scarcity and growth revisited natural resources and the environment in the new millennium. Washington, DC, USA: Resource for the Future.

Pezzey, J. (1989). .Definitions of sustainability. Discussion Paper 9, Institute of Behavioural Sciences, University of Colorado, Colorado.

Pigou, A. C. (1920). The economics of welfare. London, Macmillan.

Repetto, R., et al. (1989). Wasting assets, natural resources in the national income accounts. Washington D.C., World Resources Institute.

Robert, A. G. and Carole, L. J. (2003). Handbook of workplace spirituality and organisational performance. M. E. Sharpe, Armonk, New York: USA.

Shonk, D. J., \& Chellandurai, P. (2008). Service quality satisfaction and intent to return in event sport tourism. Journal of sport management, 22(5), 587-602. Doi: https://doi.org/10.1123/jms.22.5.587

Shostack, G. (1985). Planning the service encounter. In Czepiel, J. M. S. \& Surprenant, C. (Eds.). The service encounter. Lexington: MA, Lexington Books.

Siriram, R. (2011). A soft and hard systems approach to busines process management. System Research and Behvioural Science, 29(1), 87 - 100. Doi: 10.1002/sres.1095

Solow, R. M. (1956). A contribution to the theory of economic growth. Quarterly Journal of Economics, 70, 65-94.

University of Southern California. (2018). Organizing your social sciences research paper: Limitations of the study [Web log post]. Retrieved from http://libguides.usc.edu/writingguide

Sousa, T. T. \& Cauchick Miguel, P. A. (2015). Product-service systems as a promising approach to sustainability: Exploring the sustainable aspects of a PSS in Brazil. doi: 10.1016/j.procir.2015.02.025

Umoh, G. I., \& Ndu, E. C. (2013). The use of soft systems methodology (SSM) in evaluating the tourism industry in Nigeria: Prospects and challenges. International Journal of Business Management Review, 1(3), 111-127. 
United Nation World Tourism Organization (2017). Tourism: Key to development, prosperity and well-being UNWTO Tourism Highlights, (2017, Ed.). Retrived from https://www.e-unwto.org/doi/pdf/10.18111/9789284419029.

United Nations World Tourism Organization (2004). Sustainable development of tourism Conceptual definition (2004 ed.). Rome.

Von Bertalanffy, L. (1968). General system theory: Foundations, Development, Applications. New York: George Braziller.

Wallgren, L. G., \& Hanse, J. J. (2007). Job characteristics, motivators and stress among information technology consultants: A structural equation modeling approach. International Journal of Industrial Ergonomics, 37(1), 51-59.

Weaver, D. (2006). Sustainable tourism. Oxford: Elsevier But-terworth-Heinemann.

Wixom, B. H., \& Todd, P. A. (2005). A theoretical integration of user satisfaction and technology acceptance. Information Systems Research, 16, 85-102. Retrieved from http://refhub.elsevier.com/S0925-5273(16)30219-5/sbref162

World Bank (2006). Where is the Wealth of Nations?

World Commission on Environment and Development (WCED). (1987). Our common future: From one earth to one world. Retrieved from http://www.un-documents.net/ourcommon-future.pdf

Xu, J. D., Benbasat, I., \& Cenfetelli, R. T. (2013). Integrating service quality with system and information quality: An empirical test in the e-service context. Management Information System Quality, 37, 777-794. Retrieved from http://refhub.elsevier.com/S0925-5273(16)30219-5/sbref165

Yadzi, S. K. (2012). Sustainable tourism. American International Journal of Social Science, $1(1)$.

Zamfir, A., \& Corbos, R. A. (2015).Towards sustainable tourism development in urban areas: Case study on Bucharest as tourist destination. Journals of Sustainability, 7, 1270912722.

Zakuan, N. M., Yusof, S. M., Laosirihongthong, T., \& Shaharoun, A. M. (2010). Proposed relationship of TQM and organizational performance using structured equation modeling. Total Quality Management, 21(2), 185-203.

Zamfir, A., \& Corbos, R. A. (2015). Towards sustainable tourism development in urban areas: Case study on Bucharest as tourist destination. Journals of Sustainability, 7, 1270912722.

\section{Profile of Authors}

Eugene Chigozie Ndu is a senior academic and management consultant. He holds a B.Sc in Accounting, Post Graduate Diplomas (PGDs) in Management and Education, an MBA and MSc in Management; as well as a $\mathrm{PhD}$ in Management (with specialization in Production/Operations Management) from the University of Port Harcourt, Nigeria. He finished his $\mathrm{PhD}$ with an unbroken record of 5.00 CGPA on a 5-point scale. Dr Ndu is a Fellow of the Institute of Policy Management Development (fIPMD); member of the Operational Research Society of United Kingdom (mORSUK); member of The Academy of Management Nigeria (mTAMN); member of Hospitality and Tourism Management Association of Nigeria (mHATMAN) and a certified Hospitality and Tourism Practitioner/Consultant. He is currently a Senior Lecturer in the Department of Hospitality Management and Tourism, Faculty of Management Sciences, University of Port Harcourt. He is a well travelled conference speaker and participant; with some of his conference papers winning awards. He has equally received 
several awards and honours from respected institutions and organizations. He has published articles in learned international and local journals. His research interests span through systems engineering/management, statistical analysis, operations/production management, corporate performance, tourism/hospitality management, management information systems, entrepreneurial development, etc.

Godwin Ikpe Umoh is a well respected Professor of operations research and operations management in the University of Port Harcourt. He holds a PhD in Engineering Production, specializing in Systems, Re-Engineering and Operational Research from the University of Birmingham, England, UK (1983). His MSc is in Systems Analysis and Operational Research (1981). He has a Graduate Diploma in Systems analysis and design, from Aberdeen College, Aberdeen, Scotland, U.K. (1980). He is a sitting professor in the Department of Management, Faculty of Management Sciences, University of Port Harcourt; as well as a visiting professor to other universities. His areas of specialization include operational research applications in business, advanced statistics and statistical analysis, operations/production management, human factors engineering otherwise known as ergonomics; and management information systems. He is a Fellow of Nigerian Institute of Corporate Administration (fNICA). He is a Member of Operational Research Society of UK (mORSUK); Member, Institute of Data Processing of London (mIDPL); Member Ergonomics society of UK (mESUK\}, Member, Institute of Production Engineers, UK (mIPEUK); Member, The Academy of Management, Nigeria (mTAMN). He is well travelled; and has published in leading international journals. 